\title{
EL DESARROLLO DE LA EDUCACION PRIMARIA Y SECUNDARIA EN COLOMBIA, 1918-1957
}

\begin{abstract}
El tema de esta investigación fue escogido como tesis para ser presentado próximamente en la Universidad de Londres, a fin de optar al titulo de doctor en Historia.
\end{abstract}

\section{Situación de la problemática}

El tiempo transcurrido entre 1918 y 1957 fue el período en el cual Colombia conoció sus mayores transformaciones. La economía del país se abrió al mercado mundial con la expansión de la producción cafetera mediante un proceso de industrialización lento, vinculado a la penetración de capital extranjero, especialmente norteamericano. Al mismo tiempo, el crecimiento de la población colombiana fue acelerándose y empezó a concentrarse en las ciudades principales del país. Ese doble proceso de concentración demográfica y de desarrollo económico en ciertos polos contribuyó al empeoramiento del desequilibrio entre regiones y sectores. Sin embargo, si estas transformaciones generaron una progresión del intervencionismo' estatal y correspondieron al nacimiento de una nación dotada de los instrumentos de un Estado moderno, no produjeron cambios trascendentales en el ámbito político. En este período, la vida política se cristalizó en dos partidos dominantes sobre los cuales la Iglesia no dejó de tener una influencia considerable. El sistema educativo, superestructura de cualquier sociedad, no podía permanecer fuera de este proceso de cambios sociales, económicos y estatales: fue la época en la cual se transformó y se adapté a las nuevas dimensiones de la sociedad en la que se desempeñaba.

Muchos de los aspectos característicos de esta época han sido tema de estudios histéricos o económicos —los problemas agrarios, la industrialización, los conflictos políticos o sociales, etc. Pero al igual que en otros países, la historiografía colombiana concede poca importancia al estudio de la educación, no obstante el papel trascendental que desempeña en la evolución de la sociedad.

\section{Problemática de la investigación}

Para nosotros la problemática principal de la investigación se centra en dos ejes, los cuales decidimos estudiar en un período relativamente extenso, de 1918 a 1957, con el propósito de poder examinar su evolución. El primero consiste en analizar el papel del desarrollo económico en el fomento de la educación pública y privada y, por consiguiente, la interdependencia entre economía y educación. Emprendimos la investigación a nivel nacional y regional, a fin de medir la relación entre desarrollo económico y educación, para establecer cómo la concentración económica genera la concentración educativa, aumentando de esta manera las desigualdades regionales. Además, dentro de este contexto, estudiamos la influencia de los actores económicos (entidades privadas, asociaciones como la ANDI, la FEDECAFE, etc.) en el fomento de la educación del país.

El segundo se manifiesta por la influencia de la Iglesia en la evolución de la educación colombiana. En otros términos, examinamos el apoyo o la oposición de la lglesia a políticas que fomentaban y popularizaban la educación, y las circunstancias en las cuales se dio. Consideramos que fue una época de lucha por el poder y el control de la 
educación entre la Iglesia y el Estado, especialmente cuando los liberales estaban gobernando.

Finalmente, trataremos de definir las relaciones entre la Iglesia, los partidos políticos y los medios económicos en el campo de la educación.

\section{Metodología}

El método histórico utilizado para esta investigación se basa en fuentes escritas y en testimonios orales. En cuanto a las fuentes escritas, son de dos tipos:

1. Las fuentes nacionales, tales como la legislación, los documentos y las Memorias del Ministerio de Educación Nacional, los debates del Congreso Nacional, los archivos y las bibliotecas de asociaciones industriales, sindicales y privadas, los archivos de ciertos establecimientos educativos, los informes de misiones extranjeras y la prensa.

2. Las fuentes a nivel departamental, tales como los archivos de los departamentos, los informes de los Directores Departamentales de Educación, las publicaciones locales y parroquiales.

Los testimonios orales van a complementar esta información. Se harán entrevistas abiertas con personalidades quienes, por su función o por su conocimiento directo de la problemática, aparecieron en las fuentes escritas como de mayor importancia para entender la evolución de la educación en la época. Buscaremos entrevistar de una manera ad hoc a Ministros de Educación Nacional, Ministros Encargados de Educación, Directores Departamentales de Educación, Inspectores a nivel nacional o departamental, a maestros y profesores que hayan desempeñado estas funciones durante los años investigados.

\section{Tendencias de la educación colombiana, 1918-1957}

Durante este período la evolución de la educación colombiana se caracterizó por tres fases:

\section{1918-1934}

Fue una fase de consolidación de los logros de fines del siglo XIX y principios del siglo XX (Constitución Nacional de 1886, Concordato con la Santa Sede de 1887, Acuerdo con las misiones católicas de 1902, legislación educativa de 1903 y 1904). La educación oficial se concentraba en la enseñanza primaria y secundaria, fuera de unas pocas iniciativas laicas (Gimnasio Moderno), se confiaba a la Iglesia. La educación media industrial, comercial o agrícola era embrionaria, debido al poco desarrollo económico. Sin embargo, se nota una lenta toma de conciencia entre los responsables y los educadores del atraso educacional del país y de la necesidad de fomentar nuevas formas de educación.

\section{2. $1934-1946$}

A partir de 1934, con la llegada al poder del gobierno reformista de Alfonso López, la educación se volvió una de las preocupaciones principales del Estado: por medio de la alfabetización y la instrucción al pueblo, los gobiernos liberales esperaban modernizar el país y sacarlo de la tutela cultural de la Iglesia. Hasta 1946 se multiplicaron las iniciativas 
educativas en todos los campos. Aunque algunas parecían muy valederas, tropezaron con el cambio continuo de Ministros de Educación, la escasez del presupuesto nacional, la inexistencia de control nacional sobre los niveles departamental y municipal, el poco avance industrial y el subdesarrollo económico, la oposición de importantes sectores políticos y económicos y de la Iglesia al incremento de la intervención del Estado en la educación.

\section{1947-1957}

El fin de la segunda guerra mundial represen'ta para Colombia una época de crecimiento económico rápido, favorecido por la utilización de una serie de mecanismos que permitieron un mayor control de las fuerzas sociales por parte del Estado. En efecto, la violencia se concentré en el campo y contribuyó a la aceleración del proceso de urbanización e industrialización del país. Desde fines de los años cuarenta se nota un fuerte incremento de la educación en la enseñanza primaría y secundaria, en la cual el Estado empezó a intervenir; en la técnica y en la alfabetización rural, la Iglesia tomó un papel director. El Gobierno asocié los medios económicos a este fomento: las empresas más importantes debían crear escuelas elementales para los hijos de sus trabajadores, asociaciones como FEDECAFE desarrollaron programas educativos de formación agrícola a gran escala. Esta última fase se caracteriza, además, por la llegada a Colombia de varias misiones extranjeras (Currie, el Padre Lebret, etc.), cuya influencia en la expansión del sistema educativo no fue despreciable.

\section{Conclusión}

Hasta este punto de la investigación, la educación colombiana aparece estrechamente vinculada al desarrollo económico del país y a las necesidades de su economía. La educación no fue un factor de progreso general, ni fomenté el crecimiento económico. Al contrario, fue el despegue económico de ciertas regiones, lo que generé la necesidad de desarrollar la instrucción, a costa de un atraso creciente en otras áreas, las cuales quedaron excluidas del proceso.

Durante este período, la Iglesia compitió continuamente con el Estado en el campo educativo. Sin embargo, aparece claramente que los gobiernos conservadores consolidaron la posición de ésta en la educación, extendiendo a veces su influencia en los asuntos estatales; en cambio durante el período liberal, Iglesia y Estado se enfrentaron abiertamente por el control de la educación, provocando el retroceso de la Iglesia en el sector educativo oficial. Lo que el catolicismo perdió bajo los gobiernos liberales, lo recuperé en la década del cincuenta, durante la cual extendió su influencia a sectores más populares por medio de la alfabetización rural. Además, siguió formando hasta 1957, por lo menos, una gran parte de la élite del país, manteniendo así su influencia en el desarrollo futuro de la Nación. 